\title{
MONOTERAPIJOS IR KOMBINUOTOS SEDACIJOS PROPOFOLIU PALYGINIMAS VIRŠKINAMOJO TRAKTO ENDOSKOPINIŲ PROCEDŪRŲ METU
}

\author{
Viktorija Kenstavičiūtė ${ }^{1}$, Roberta Buginytė ${ }^{1}$, Asta Mačiulien $\dot{\mathbf{e}}^{2}$ \\ ${ }^{1}$ Lietuvos sveikatos mokslu universiteto Medicinos akademijos Medicinos fakultetas, \\ ${ }^{2}$ Lietuvos sveikatos mokslu universiteto Medicinos akademijos Anesteziologijos klinika
}

Raktažodžiai: virškinamojo trakto endoskopija, propofolis, sedacija.

\begin{abstract}
Santrauka
Virškinamojo trakto (VT) ligų diagnostikai ir gydymui vis plačiau taikomos endoskopinès procedūros. Jų metu pacientų patiriamą diskomfortą ir nerimą mažina adekvati sedacija ir analgezija. Sedacijai sukelti dažniausiai naudojamas medikamentas yra propofolis. Jis yra trumpai veikiantis, neturintis analgezinio efekto, todèl dažnai naudojamas kombinuojant su opioidais ir (ar) benzodiazepinais. Šiame straipsnyje analizuojami klinikiniai tyrimai, lyginantys monoterapiją propofoliu (MTP) ir kombinuotą sedaciją propofoliu (KTP), kai kartu su propofoliu naudojamas midazolamas, fentanilis ir (arba) ketaminas. Tyrimo tikslas - palyginti abiejų metodų ịtaką nepageidaujamų reakcijų pasireiškimui, atsigavimo laiko trukmei po procedūros bei gydytojų ir pacientų pasitenkinimui atlikta procedūra. Tyrimo rezultatai parodè, kad VT endoskopinių procedūrų metu taikant monoterapiją propofoliu hipoksijos ir hipotenzijos rizika yra didesne, nei taikant kombinuotą terapiją propofoliu. Sedacijos pradžia ir atsigavimo laikas po procedūros yra trumpesnis, kai propofolis naudojamas vienas. Gydytojų ir pacientų pasitenkinimas procedūra nuo pasirinkto sedacijos metodo nepriklauso.
\end{abstract}

\section{İvadas}

Pastaraisiais dešimtmečiais endoskopinès procedūros vis plačiau taikomos virškinamojo trakto (VT) ligų diagnostikai ir gydymui. Kad jos nesukeltų pacientams papildomo diskomforto ir būtų užtikrinta sklandi tyrimo eiga, procedūros metu reikalinga adekvati sedacija ir analgezija [1-3]. Idealus sedacijai naudojamas medikamentas turi pasižymèti greita veikimo pradžia, trumpu veikimu, nesudètingu titravimu bei sukelti tik minimalų poveikị širdies kraujagyslių ir kvėpavimo sistemoms [4]. Dažniausiai VT endoskopinių procedūrų metu naudojamas medikamentas yra propofolis [5]. Dẻl savo lipofiliškų savybių jis lengvai prasiskverbia per kraujo-smegenų barjerą ir lemia greitą sedacijos pradžią ( 30 - 60 s.), o trumpas skilimo pusperiodis - greitą eliminaciją [6]. Šis vaistas yra populiarus, kai siekiama greito paciento atsigavimo po ambulatoriškai atliktų VT endoskopijų. Kita vertus, daugelis naudojamų medikamentų negali visiškai užtikrinti tinkamos sedacijos ir analgezijos. Ne išimtis ir propofolis, kuris sukelia tik trumpą sedacini poveikį, todèl dažnai yra derinamas su opioidais, kurie papildomai malšina skausmą [4] ir (ar) benzodiazepinais.

Diskutuojama, kuris sedacijos būdas saugesnis ir efektyvesnis. Vieni autoriai nurodo, kad sumažinus propofolio dozę, mažèja su sedacija susijusių širdies ir kraujagyslių sistemos komplikacijų rizika, o pacientų pasitenkinimas procedūra išlieka toks pat [7]. Kitų tyrejjų duomenimis, atsigavimo laikas po procedūros yra trumpesnis, kai taikoma sedacija propofolio monoterapija [8-11].

Siekiant ịvertinti šių sedacijos metodų skirtumus, atlikta nemažai tyrimų, tačiau jų išvados yra diskutuotinos, o pateikti rezultatai gana prieštaringi. Išlieka aktualus klausimas, ar geriau rinktis sedaciją propofolio monoterapija (MTP), ar kombinuoti ši medikamentą su kitais vaistais VT endoskopinių procedūrų metu.

Tyrimo tikslas - atlikti sisteminę literatūros šaltinių duomenų analizę, siekiant palyginti propofolio monoterapiją (MTP) ir kombinuotą terapiją, kai propofolis naudojamas kartu su midazolamu, fentaniliu ir (arba) ketaminu (KTP). İvertinti abiejų metodų ịtaką nepageidaujamų reakcijų pasireiškimui, atsigavimo laiko trukmei po procedūros bei gydytojų ir pacientų pasitenkinimui atlikta procedūra.

\section{Tyrimo medžiaga ir metodai}

Literatūros šaltinių paieška atlikta elektroninèse $\mathrm{Pu}-$ bMed, Cochrane, UpToDate, ClinicalKey (Medline) duo- 
menų bazėse. Analizei atrinkti 2011-2021 metais publikuoti atsitiktinių imčių tyrimai. Paieškai naudoti raktažodžiai ar jų deriniai: sedation, propofol, gastrointestinal endoscopy, randomized controlled trial. Straipsnių atranka buvo vykdoma nepriklausomai dviejų tyrejjų pagal įtraukimo ir atmetimo kriterijus (1 lentelè). I šią sisteminę literatūros apžvalgą neįtraukti apžvalginiai straipsniai, atvejų aprašymai, redaktorių komentarai ar rekomendacijos, laboratoriniai moksliniai tyrimai ir kiti neaktualūs tyrimai. Detaliai analizei iš viso atrinkta 12 straipsnių (1 lentelè).

Šia sistemine literatūros apžvalga siekiama palyginti monoterapiją propofoliu (MTP) ir kombinuotą terapiją propofoliu (KTP). Atskirai vertinamas pasireiškusių nepageidaujamų reakcijų (hipoksijos, hipotenzijos ir aritmijų) dažnumas. Lyginta atsigavimo po procedūros trukmė skirtingų sedacijos taktikų metu. Vertinamas gydytojų ir pacientų požiūris ị atliktą procedūrą, taikant sedaciją propofolio monoterapija ir kombinuota terapija. Duomenys sukaupti specialiai šiam darbui sukurtoje duomenų bazèje ir statistiškai išanalizuoti, naudojant MS Excel 2015 ir Review Manager 5.4 programas.

\section{Tyrimo rezultatai ir jų aptarimas}

Duomenų bazių paieškos sistemose pagal metodikoje pateiktus raktinius žodžius iš viso rasti 469 straipsniai $(\mathrm{Pu}-$ bMed - 190, ClinicalKey (Medline) - 85, Cochrane - 45, UpToDate - 149). Iš jų 326 straipsniai publikuoti per pastaruosius 10 metų. Mokslinių literatūros šaltinių tinkamumas buvo nepriklausomai ịvertintas atskirai dviejų tyrejų pagal iš anksto 1 lentelèje pateiktus kriterijus. Iš viso analizei atrinkta 12 straipsnių, kurių apibendrinti duomenys pateikti 2 lentelèje.

Išnagrinejjus straipsnius nustatyta, kad indukcijos trukmè iki sedacijos pradžios buvo statistiškai reikšmingai mažesne naudojant MTP (3,82 min. $\pm 2,94$ min.), lyginant su KTP (4,03 $\min . \pm 1,49 \min$. $)(\mathrm{p}<0,05)$.
2 lentelè. İtrauktų atsitiktinių imčių tyrimų santrauka.

$N$ - pacientu skaičius, $N / D$ - nèra duomenu, *Sertifikuota registruota anestezijos slaugytoja, ESD - endoskopine submukozinè disekcija, FGDS - fibrogastroduodenoskopija, ERCP - endoskopinè retrogradinè cholangiopankreatoskopija, EUS

\begin{tabular}{|c|c|c|c|c|}
\hline \begin{tabular}{|l} 
Straipsnis \\
(autorius, metai) \\
Chun (2012)
\end{tabular} & $\begin{array}{c}\text { Atsakingas } \\
\text { už anesteziją } \\
\text { N/D }\end{array}$ & $\begin{array}{c}\text { Endoskopijos tipas } \\
\text { ESD }\end{array}$ & $\begin{array}{c}\text { Sedacija } \\
P \\
P+\mathrm{MDZ}\end{array}$ & $\begin{array}{c}\text { Pacientai, N } \\
67 \\
68\end{array}$ \\
\hline Lee(2012) & Slaugytoja* & EUS, ERCP & $\begin{array}{c}\mathrm{P} \\
\mathrm{P}+\mathrm{MDZ} / \mathrm{F}\end{array}$ & $\begin{array}{l}104 \\
102 \\
\end{array}$ \\
\hline Molina-Infante (2012) & Slaugytoja* & Kolonoskopija & $\begin{array}{c}\mathrm{P} \\
\mathrm{P}+\mathrm{MDZ}\end{array}$ & $\begin{array}{l}58 \\
61\end{array}$ \\
\hline Poulos (2013) & Slaugytoja* & FGDS, Kolonoskopija & $\begin{array}{c}\mathrm{P} \\
\mathrm{P}+\mathrm{MDZ} / \mathrm{F}\end{array}$ & $\begin{array}{l}330 \\
282\end{array}$ \\
\hline Chan (2014) & $\mathrm{N} / \mathrm{D}$ & $\begin{array}{c}\text { Kolonoskopija } \\
\text { FGDS }\end{array}$ & $\begin{array}{c}\mathrm{P} \\
\mathrm{P}+\mathrm{MDZ} \\
\mathrm{P} \\
\mathrm{P}+\mathrm{MDZ}\end{array}$ & $\begin{array}{l}60 \\
60 \\
50 \\
50\end{array}$ \\
\hline Tandon (2014) & Anesteziologas & FGDS & $\begin{array}{c}\mathrm{P} \\
\mathrm{P}+\mathrm{K}\end{array}$ & $\begin{array}{l}135 \\
135\end{array}$ \\
\hline Hsu (2015) & $\begin{array}{c}\text { Slaugytoja*, } \\
\text { anesteziologas }\end{array}$ & Kolonoskopija, FGDS & $\begin{array}{c}\mathrm{P} \\
\mathrm{P}+\mathrm{MDZ} / \mathrm{F}\end{array}$ & $\begin{array}{l}50 \\
50 \\
\end{array}$ \\
\hline Fassoulaki (2015) & Anesteziologas & ERCP & $\begin{array}{c}\mathrm{P} \\
\mathrm{P}+\mathrm{F}\end{array}$ & $\begin{array}{l}57 \\
59\end{array}$ \\
\hline Julian-Gomez (2018) & Slaugytoja* & FGDS & $\begin{array}{c}\mathrm{P} \\
\mathrm{P}+\mathrm{MDZ}\end{array}$ & $\begin{array}{l}42 \\
41\end{array}$ \\
\hline Singh (2018) & Anesteziologas & EUS & $\begin{array}{c}\mathrm{P} \\
\mathrm{P}+\mathrm{K} / \mathrm{F}\end{array}$ & $\begin{array}{l}68 \\
71 \\
\end{array}$ \\
\hline El-Sayed (2019) & $\mathrm{N} / \mathrm{D}$ & EUS & $\begin{array}{c}\mathrm{P} \\
\mathrm{P}+\mathrm{K}\end{array}$ & $\begin{array}{l}30 \\
30\end{array}$ \\
\hline Garg (2019) & Anesteziologas & ERCP & $\begin{array}{c}\mathrm{P} \\
\mathrm{P}+\mathrm{K}\end{array}$ & $\begin{array}{l}30 \\
30\end{array}$ \\
\hline
\end{tabular}

1 lentelè. Literatūros šaltinių įtraukimo ị sisteminę apžvalgą ir atmetimo kriterijai.

$V T$ - virškinamasis traktas

\begin{tabular}{|l|l|}
\hline Itraukimo kriterijai & Atmetimo kriterijai \\
\hline Vertinami tik atsitiktinių imčių kli- & Sedacija taikoma kitų endos- \\
nikiniai tyrimai; & kopinių procedūrų, nesusiju- \\
Tyrimai, kuriuose lyginama mono- & sių su VT endoskopijomis, \\
terapija propofoliu ir kombinuota & metu; \\
terapija su propofoliu; & Tyrimas yra nebaigtas (ban- \\
Atlikti tyrimai seduotiems pacien- & domasis arba planuojamas); \\
tams, kuriems atliekama tik virški- & Straipsniai, paskelbti iki \\
namojo trakto endoskopija; & 2011 metų; \\
Tyrimo imtyje įtraukti tik suaugu- & Straipsniai, aprašantys tyri- \\
sieji; & mus, i kuriuos įtraukti vai- \\
Straipsniai publikuoti 2011- 2021 & kai; \\
m. (ịskaitytinai); & Pasikartojantys straipsniai \\
Straipsniai anglų kalba; & (duplikacija). \\
Prieinami viso teksto straipsniai. & \\
\hline
\end{tabular}


Atsigavimo laikas. Ivertinus analizuotus straipsnius paaiškejjo, kad diagnostinių procedūrų metu atsigavimo laikas tarp MTP ir KTP grupių reikšmingai skyrèsi $(\mathrm{p}<0,05)$. Naudojant MTP, pacientų atsigavimo laikas nuo procedūros pabaigos buvo greitesnis (truko $11,12 \mathrm{~min} . \pm 2,94 \mathrm{~min}$., o po KTP - 15,3 min. $\pm 2,83 \mathrm{~min}$. Kai propofolis buvo kombinuotas su midazolamu, stebèta ilgesnè atsigavimo trukmè, nei naudojant propofoli kartu su ketaminu $(\mathrm{p}<0,05)$.

Komplikacijos, susijusios su kvèpavimo sistema hipoksija. Taikant MTP, hipoksija buvo nustatyta 12,8 \pm 6,7 proc., o KTP metu 5,4 $\pm 2,5$ proc. atvejų. Šis skirtumas vertintas statistiškai nereikšmingu $(\mathrm{p}>0,05)$ ir nustatytas duomenų heterogeniškumas (RR, 1,62; 95 proc. CI, 0,80 iki 3,25 ; I2 $=50$ proc.) (1pav.). Tai nustatyta nepriklausomai nuo to, kuris medikamentas buvo taikytas kombinuotos terapijos metu ( $p>0,05)$, tačiau naudojant propofoli kartu su ketaminu, hipoksija pasireiškè rečiau $(4,9 \pm 1,5$ proc. atvejų), nei derinant propofolị su midazolamu $(5,8 \pm 3,4$ proc. atvejų, $\mathrm{p}<0,05)$.

Komplikacijos, susijusios su širdies ir kraujagyslių sistema - hipotenzija. Hipotenzijos pasireiškimo dažnumas abiejų sedacijos metodų metu statistiškai reikšmingai nesiskyrè ( $\mathrm{p}>0,05)$, kartu pasireiškè duomenu heterogeniškumas (RR, 1,$29 ; 95$ proc. CI, 0,65 iki 2,56; $\mathrm{I}_{2}=71$ proc.) ( 2 pav.). Taikant MTP, hipotenzija pasireiškè $15,5 \pm 10,9$ proc., o KTP metu $-12,4 \pm 10,9$ proc. atvejų. Hipotenzijos dažnumas su propofoliu naudojant midazolamą buvo didesnis ( $8,3 \pm 6$ proc.), nei derinant propofoli su ketaminu $(6,3 \pm 0,5$ proc., $p<0,05)$.

Paciento ir gydytojo požiūris ị procedūrą. Keturiuose iš analizuotų tyrimų gydytojų endoskopuotojų ir pacientų pasitenkinimas atliekama procedūra buvo didesnis, kai propofolis buvo kombinuotas su kitu medikamentu. Likusiuose tyrimuose procedūra vertinta vienodai palankiai. Apibendrinus duomenis, statistiškai reikšmingo skirtumo tarp MTP ir KTP sedacijos metodų nenustatyta $(\mathrm{p}<0,05)$.

\section{Diskusija}

Atlikto tyrimo rezultatai parodè, kad esminio skirtumo tarp MTP ir KTP nèra. Sedacijos pradžios ir atsigavimo trukmè, galimų komplikacijų dažnumas bei pacientų ir gydytojų pasitenkinimas atlikta procedūra buvo vienodas abiejose grupèse.

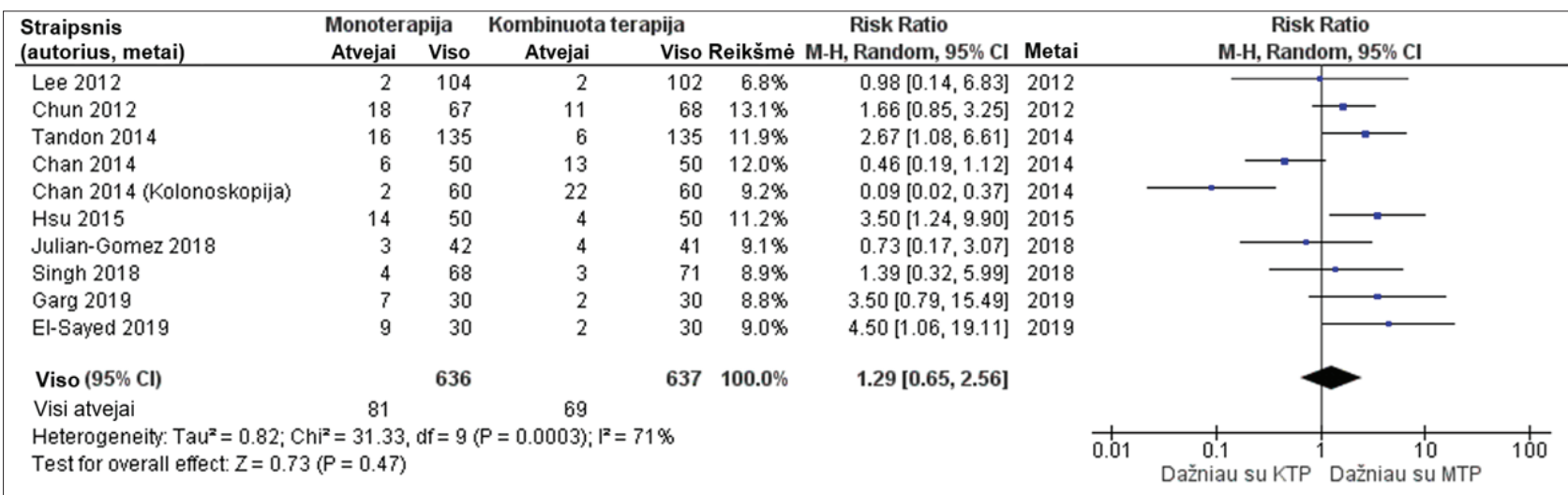

1 pav. Foresto diagrama, iliustruojanti hipoksijos pasireiškimo dažnumą skirtinguose tyrimuose, atliekant MTP ir KTP

\begin{tabular}{|c|c|c|c|c|c|c|c|c|c|c|c|}
\hline \multirow{2}{*}{$\begin{array}{l}\text { Straipsnis } \\
\text { (autorius, metai) }\end{array}$} & \multicolumn{2}{|c|}{ Monoterapija propofoliu } & \multicolumn{2}{|c|}{ Kombinuota terapija } & \multirow{2}{*}{ Reikšmè } & \multirow{2}{*}{$\begin{array}{l}\text { Risk Ratio } \\
\text { I, Random, } 95 \% \mathrm{Cl}\end{array}$} & \multirow[b]{2}{*}{ Metai } & \multirow{2}{*}{\multicolumn{4}{|c|}{$\begin{array}{c}\text { Risk Ratio } \\
\text { M-H, Random, } 95 \% \mathrm{Cl}\end{array}$}} \\
\hline & Atvejai & Viso & Atvejai & Viso & & & & & & & \\
\hline Chun 2012 & 4 & 67 & 1 & 68 & $7.0 \%$ & $4.06[0.47,35.38]$ & 2012 & & & & \\
\hline Lee 2012 & 7 & 104 & 6 & 102 & $14.4 \%$ & $1.14[0.40,3.29]$ & 2012 & & & & \\
\hline Tandon 2014 & 19 & 135 & 4 & 135 & $14.5 \%$ & $4.75[1.66,13.59]$ & 2014 & & & & \\
\hline Chan 2014 & 0 & 50 & 6 & 50 & $4.7 \%$ & $0.08[0.00,1.33]$ & 2014 & $\longleftarrow$ & & & \\
\hline Chan 2014 (Kolonoskopija) & 0 & 60 & 6 & 60 & $4.7 \%$ & $0.08[0.00,1.34]$ & 2014 & $\leftarrow$ & & & \\
\hline Hsu 2015 & 8 & 50 & 3 & 50 & $12.6 \%$ & $2.67[0.75,9.47]$ & 2015 & & & & \\
\hline Singh 2018 & 5 & 68 & 4 & 71 & $12.6 \%$ & $1.31[0.37,4.66]$ & 2018 & & & & \\
\hline Julian-Gomez 2018 & 3 & 42 & 4 & 41 & $11.3 \%$ & $0.73[0.17,3.07]$ & 2018 & & & & \\
\hline El-Sayed 2019 & 5 & 30 & 1 & 30 & $7.4 \%$ & $5.00[0.62,40.28]$ & 2019 & & & & \\
\hline Garg 2019 & 7 & 30 & 2 & 30 & $10.9 \%$ & $3.50[0.79,15.49]$ & 2019 & & & & \\
\hline Viso $(95 \% \mathrm{Cl})$ & & 636 & & 637 & $100.0 \%$ & $1.62[0.80,3.25]$ & & & & & \\
\hline Visi atvejai & 58 & & 37 & & & & & & & & \\
\hline \multicolumn{5}{|c|}{$\begin{array}{l}\text { Heterogeneity: } \operatorname{Tau}^{2}=0.59 ; \mathrm{Chi}^{2}=18.13, \mathrm{df}=9(P=0.03) ; \mathrm{I}^{2}=50 \% \\
\text { Test for overall effect: } Z=1.35(P=0.18)\end{array}$} & & & & 0.01 & $\begin{array}{c}0.1 \\
\text { Dažniau su KTP }\end{array}$ & $\begin{array}{c}10 \\
\text { Dažniau su MTP }\end{array}$ & 100 \\
\hline
\end{tabular}

2 pav. Foresto diagrama, iliustruojanti hipotenzijos pasireiškimo dažnumą skirtinguose tyrimuose, atliekant MTP ir KTP 
Sedacijos pradžia ir pacientų atsigavimo laikas po procedūros tarp analizuotų grupių statistiškai reikšmingai nesiskyrè. Daugumoje nagrinètų tyrimų buvo stebèta nežymiai greitesnè sedacijos pradžia ir trumpesnè atsigavimo trukmè, naudojant propofolio monoterapiją. Atskirai vertinant kombinuotos terapijos medikamentus, stebeta ilgesnè sedacijos pradžia ir sedacijos trukmè propofolị derinant su midazolamu, nei su ketaminu. Pavyzdžiui, J. Molina-Infante ir kt. [10] ir W. Chan ir kt. [12] tyrimuose nurodoma, kad skiriant midazolamą kartu su propofoliu, pailgèjo paciento atsigavimo trukmè, o po procedūros pacientai skundèsi ilgiau išliekančiu mieguistumu. Tokie rezultatai gauti galimai dèl lètesnio midazolamo klirenso, lyginant su ketaminu (atitinkamai 6,4-11 $\mathrm{ml} / \mathrm{min} / \mathrm{kg}$ ir $12-20 \mathrm{ml} / \mathrm{min} / \mathrm{kg}$ ).

Komplikacijos, susijusios su širdies ir kraujagyslių sistema, tarp abiejų analizuotų grupių statistiškai reikšmingai nesiskyrè. Vis dèlto, El Sayed ir kt. [17] tyrimo metu stebèta, kad hipotenzijos dažnumas yra mažesnis kombinuotos terapijos metu naudojant ketaminą. Dèl periferinès vazodilatacijos ir neigiamo inotropinio poveikio propofolis mažina arterini kraujospūdị, o dèl savo simpatomimetinių savybių ketaminas yra linkęs stabilizuoti kraujospūdị. Šis skirtumas tarp kombinuotos ir monoterapijos propofoliu, nebuvo statistiškai reikšmingas. M. Tandon ir kt. [13] straipsnyje teigiama, jog greta simpatomimetinio ir analgezinio poveikio ketaminas gali padèti palaikyti kvépavimo takų praeinamumą sedacijos ir anestezijos metu, apsaugant nuo propofolio sukeltos burnos ir ryklès raumenų atonijos. Iš visų i čią apžvalgą ịtrauktų tyrimų tiktai W. Chan ir kt. [12] nustate, kad taikant nuolatinę kontroliuojamą propofolio infuziją (automatine švirkštine pompa), hipoksijos ir hipotenzijos epizodai pasitaikè rečiau, lyginant su kombinuota sedacija propofoliu ir midazolamu. Skiriant propofoli, nuolatine infuzija kraujo plazmoje palaikoma propofolio koncentracija, kuri neviršija terapinès dozès, išvengiama staigiu propofolio koncentracijos svyravimų, kurie pasireiškia skiriant propofolį boliusu.

Pacientų ir gydytojų pasitenkinimas atlikta procedūra statistiškai reikšmingai tarp abieju sedacijos metodu nesiskyrè, tačiau dèl subjektyvaus anketų vertinimo, stebimi nežymūs pacientų nuomonių skirtumai. T. Lee ir kt. [9] ivvertino, kad propofolio monoterapijos metu pacientai jaute didesnị skausmą ir dažniau prisiminè endoskopo ịvedimą bei pašalinimą, nei kombinuotos terapijos su midazolamu ar fentaniliu metu. Atitinkamai ir gydytojų pasitenkinimas šia procedūra buvo mažesnis, kadangi procedūros metu stebèti minimalūs papildomi pacientu judesiai. Panašią problemą savo tyrime aprašè W. Chan ir kt. [12], kai taikant nuolatinès propofolio infuzijos metodiką, propofolio monoterapijos metu endoskopinè procedūra buvo laikinai sustabdyta dèl paciento judesių. J. Poulos ir kt. [11] savo tyrime palankiau vertino monoterapiją propofoliu, kadangi didesnè pacientų dalis neprisiminè procedūros bei greičiau visiškai po jos atsigavo. Keturiuose iš analizuotų tyrimų sedacijos valdymas buvo patikètas slaugytojai, trijuose nebuvo detalizuotas šis aspektas, likusiuose sedaciją atliko gydytojas anesteziologas. Dèl duomenų trūkumo negalëjome ịvertinti, ar sedaciją atliekančio asmens kvalifikacija ir patirtis galëjo turèti įtakos endoskopuotojų ir pacientų pasitenkinimui anestezija.

\section{Išvados}

1. Nustatyta, kad taikant sedaciją propofolio monoterapija, sedacijos pradžia ir atsigavimo trukmè po endoskopinès procedūros yra greitesnè.

2. Taikant monoterapiją propofoliu, hipoksijos ir hipotenzijos atvejų rizikos yra nereikšmingai didesnès, lyginant su kombinuota sedacija.

3. Pacientų ir endoskopuotojų pasitenkinimas atlikta procedūra išlieka vienodas, nepriklausomai nuo pasirinkto sedacijos metodo.

\section{Literatūra}

1. Radaelli F, Meucci G, Sgroi G, Minoli G. Technical performance of colonoscopy: the key role of sedation/analgesia and other quality indicators. Am J Gastroenterol 2008;103(5):1122-30. https://doi.org/10.1111/j.1572-0241.2007.01778.x

2. Seip B, Bretthauer M, Dahler S, Friestad J, Huppertz-Hauss G, Høie O, et al. Patient satisfaction with on-demand sedation for outpatient colonoscopy. Endoscopy 2010;42(8):639-46. https://doi.org/10.1055/s-0030-1255612

3. Aljebreen AM. Unsedated endoscopy: is it feasible? Saudi J Gastroenterol 2010;16(4):243-4. https://doi.org/10.4103/1319-3767.70605

4. Norkienė I., Vosylius S. Procedūrinè sedacija ir analgezija. Rekomendacijos. Lietuvos anesteziologų reanimatologų draugija, 2019:13.

5. Lin OS. Sedation for routine gastrointestinal endoscopic procedures: a review on efficacy, safety, efficiency, cost and satisfaction. Intest Res 2017;15(4):456-66. https://doi.org/10.5217/ir.2017.15.4.456

6. Nishizawa T, Suzuki H. Propofol for gastrointestinal endoscopy. United Eur Gastroenterol J 2018;6(6):801-5. https://doi.org/10.1177/2050640618767594

7. Julián-Gómez L, Fuentes-Coronel A, López-Ramos C, OchoaSangrador C, Fradejas-Salazar P, Martín-Garrido E, et al. A clinical trial comparing propofol versus propofol plus midazolam in diagnostic endoscopy of patients with a low anesthetic risk. Rev Esp Enfermedades Dig 2018;110(11):691-8. https://doi.org/10.17235/reed.2018.5289/2017

8. Chun SY, Kim KO, Park DS, Kim SY, Park JW, Baek IH, et al. Safety and efficacy of deep sedation with propofol alone or combined with midazolam administrated by nonanesthe- 
siologist for gastric endoscopic submucosal dissection. Gut Liver 2012;6(4).

https://doi.org/10.5009/gnl.2012.6.4.464

9. Lee TH, Lee CK, Park SH, Lee SH, Chung IK, Choi HJ, et al. Balanced propofol sedation versus propofol monosedation in therapeutic pancreaticobiliary endoscopic procedures. Dig Dis Sci 2012;57(8):2113-21.

https://doi.org/10.1007/s10620-012-2234-0

10. Molina-Infante J, Dueñas-Sadornil C, Mateos-Rodriguez JM, Perez-Gallardo B, Vinagre-Rodríguez G, Hernandez-Alonso $\mathrm{M}$, et al. Nonanesthesiologist-administered propofol versus midazolam and propofol, titrated to moderate sedation, for colonoscopy: a randomized controlled trial. Dig Dis Sci 2012;57(9):2385-93.

https://doi.org/10.1007/s10620-012-2222-4

11. Poulos JE, Kalogerinis PT, Caudle JN. Propofol compared with combination propofol or midazolam/fentanyl for endoscopy in a community setting. AANA J 2013;81(1):31-6. www.aana. com/aanajournalonline

12. Chan WH, Chang SL, Lin CS, Chen MJ, Fan SZ. Targetcontrolled infusion of propofol versus intermittent bolus of a sedative cocktail regimen in deep sedation for gastrointestinal endoscopy: comparison of cardiovascular and respiratory parameters. J Dig Dis 2014;15(1):18-26.

https://doi.org/10.1111/1751-2980.12101

13. Tandon M, Pandey VK, Dubey GK, Pandey CK, Wadhwa N. Addition of sub-anaesthetic dose of ketamine reduces gag reflex during propofol based sedation for upper gastrointestinal endoscopy: a prospective randomised double-blind study. Indian J Anaesth 2014;58(4):436-41.

https://doi.org/10.4103/0019-5049.138981

14. Hsu CD, Huang JM, Chuang YP, Wei HY, Su YC, Wu JY, et al. Propofol target-controlled infusion for sedated gastrointestinal endoscopy: a comparison of propofol alone versus propofolfentanyl-midazolam. Kaohsiung J Med Sci 2015;31(11):580-4. https://doi.org/10.1016/j.kjms.2015.09.004

15. Fassoulaki A, Iatrelli I, Vezakis A, Polydorou A. Deep sedation for endoscopic cholangiopancreatography with or without pre or intraprocedural opioids: a double-blind randomised controlled trial. Eur J Anaesthesiol 2015;32(9):602-8.

https://doi.org/10.1097/EJA.0000000000000187

16. Singh SA, Prakash K, Sharma S, Dhakate G, Bhatia V. Comparison of propofol alone and in combination with ketamine or fentanyl for sedation in endoscopic ultrasonography. Korean J Anesthesiol 2018;71(1).

https://doi.org/10.4097/kjae.2018.71.1.43

17. El-Sayed Ahmed El-Feqy B, Mahmoud Mohamed El-Garhey A, El-Azeim Maamon Dawoud A. Comparative study between ketamine and propofol combination versus propofol alone for sedation of patients undergoing upper gastrointestinal tract endoscopy. Al-Azhar Med J 2019;48(4):377-86.

18. Garg A, Prasad MK, Jheetay GS, Varshney RK, Choudhary AK, Garg HS. Comparison of propofol alone and propofolketamine mixture for sedation during endoscopic retrograde cholangiopancreatography (ercp): a randomised study. J Clin diagnostic Res 2019.

https://doi.org/10.7860/JCDR/2019/40683.12768

\section{MONOTHERAPY AND PROPOFOL COMBINATION THERAPY IN GASTROINTESTINAL ENDOSCOPIES: SYSTEMIC LITERATURE REVIEW \\ V. Kenstavičiūtè, R. Buginytė, A. Mačiulienè}

Keywords: digestive system, gastrointestinal endoscopy, propofol, sedation.

Summary

Endoscopic procedures are becoming more popular in the diagnosis and treatment of gastrointestinal diseases. Adequate sedation and analgesia are used during these procedures to minimize patients' discomfort and anxiety. Propofol is a drug of choice in these cases most commonly. However, because of its short effect, Propofol can be used in combination with opioids and/or benzodiazepines. This systematic literature review analyzes scientific studies comparing propofol monotherapy (MTP) with propofol combination therapy (CTP) when midazolam, fentanyl and (or) ketamine is used in combination with propofol. The aim of the study was to consider the influence of both methods on the incidence of adverse reactions, the length of recovery time after treatment, and the satisfaction of doctors and patients with the procedure performed. The results of this systematic review demonstrated the following: the risk of hypoxia and hypotension with propofol monotherapy is higher than with CTP; the onset of sedation and recovery time after the procedure is shorter with propofol alone; the physicians' and patients' satisfaction with the procedure does not depend on the chosen sedation method.

Correspondence to: viktorija.kenstaviciute@stud.lsmu.lt

Gauta 2021-03-25 